This is a 2008 extension and update of an overview which appeared in J. Blasius, J. Hox, E. de Leeuw \& P. Schmidt (Eds.), Social science methodology in the new millennium. Opladen, FRG: Leske + Budrich., 2002, CD-ROM

\title{
The Effect of Computer-Assisted Interviewing on Data Quality: A Review of the Evidence
}

Edith D. de Leeuw ${ }^{1}$

MethodikA/Department of Methodology and Statistics, Utrecht University

\begin{abstract}
Computer assisted telephone interviewing, and to a lesser degree, computer assisted face-to-face interviewing, are by now widely used in survey research. Recently, self-administered forms of computer-assisted data collection, such as web surveys, have become extremely popular. Advocates of computer assisted interviewing (CAI) claim that its main advantages are improved data quality and lower costs. This paper summarizes what is currently known about computer assisted data collection methods. The emphasis is on data quality and the influence of technology on the respondent.
\end{abstract}

Key words: Computer assisted data collection, CADAC, CASIC, CATI, CAPI, CASI, DBM, web surveys, data quality, acceptance, usability, human factor

\section{Introduction}

Whether computer assisted data collection should be used in survey research seems no longer an issue of debate. Computer assisted methods have replaced paper-and-pen methods at an increasing pace, and in Europe and North America many government survey organizations now employ these new methods for their surveys (De Leeuw, Nicholls, Andrews, \& Mesenbourg, 2000). Large market research organizations and academic research organizations are following (Blyth, 1998; Collins, Sykes \& O'Muircheartaigh, 1998). Characteristic of computer assisted data collection is that questions are read from the computer screen, and that responses are entered directly into the computer, either by an interviewer or by the respondent self. An interactive program presents the questions in the proper order, which may be different for different (groups of) respondents. For a historical overview see Couper and Nicholls (1998). For a taxonomy of various forms of computer assisted data collection methods, see Appendix A; a more detailed overview can be found in De Leeuw and Nicholls (1996) and in De Leeuw, Hox, and Snijkers (1998).

Computer Assisted Telephone Interviewing (CATI) is the oldest form, and is also the most prevalent. CATI is now the dominant method for telephone surveys in market research, government organizations and universities, although paper-and-pencil methods are still being used with good results in small survey organizations and for short surveys. For face-to-face interviews, Computer Assisted Personal Interviewing (CAPI) is rapidly gaining in popularity and is already widely used in government statistical agencies and market research firms, and

\footnotetext{
${ }^{1}$ The author thanks Jean Martin, Peter Lynn, Tony Manners, Joop Hox, and Bill Nicholls II for their helpful comments.
} 
research departments at universities are following. The later were very quick to see the potential of CAPI when surveying special populations, especially in combination with Computer Assisted Self Interviewing (CASI): a computer assisted form of the self-administered questionnaire (for an overview see De Leeuw, E., Hox, J., \& Kef, S. 2003).

Computerized self-administered data collection takes many forms. The oldest is the electronic questionnaire or electronic test, which is used in the medical and psychological sciences (cf. Weisband \& Kiesler, 1996). In survey research, CASI is frequently used during CAPI-sessions on sensitive topics, when the interviewer hands over the computer to the respondent for a short period, but remains available for instructions and assistance. This is equivalent to the traditional procedure where an interviewer might give a paper questionnaire to a respondent to fill in privately. A very promising variant is Audio-CASI, where the respondent listens to the questions read by a computer-controlled digitized voice over a headset, and at the same time sees the question on the computer screen. This helps overcome literacy problems with special populations and guarantees the privacy of the respondent (cf. Turner et al, 1998; Johnston \& Walton, 1995).

For the traditional mail survey computer assisted equivalents have been developed too. Disk-by-Mail has been used on a regular basis for some time, especially in establishment surveys, and methodological knowledge on how to implement a successful Disk-by-Mail survey is available (e.g., Ramos, Sedivi, \& Sweet, 1998; Saltzman, 1992; Witt \& Bernstein, 1992; Van Hattum \& De Leeuw, 1999). In a Disk-by-Mail survey (DBM) a disk containing the questionnaire and a self-starting interview program is mailed to the respondent via the postal service. The respondent runs the program on his or her own computer and returns the diskette containing the completed questionnaire.

Electronic mail surveys (EMS), Internet surveys and web surveys differ from DBM in the sense that respondents receive the request and return the survey data electronically through the Internet. This is a field still very much in development, and its usefulness depends on the Internet penetration in specific countries. In some countries, such as, the USA, Scandinavia, and the Netherlands, the Internet penetration is relatively high, and web surveys are being done on a regular basis; in other countries, web surveys are only possible with special populations, but the experience is positive and a multimode approach has proved to be successful (Clayton \& Werking, 1998; Schaefer \& Dillman, 1998; Couper, 2000, Dillman, 2000; De Leeuw \& Hox, 2008; Lozar Manfreda \& Vehovar, 2008). Another way to overcome the limited computer access in web surveys, is computer assisted panel research. A panel of households is selected and computers and communication equipment are provided by the research institute. Surveys are sent electronically to the household members on a regular basis, and after completion are sent back automatically. This approach proved successful for consumer panels in the Netherlands (Saris, 1998). For an illustrative example see the CentERpanel (see www.centerdata.nl), located at Tilburg University

One of the main reasons that computer assisted data collection has become popular so quickly was the general expectation that it would improve data quality and efficiency and reduce costs (cf. Blyth, 1998; De Leeuw \& Nicholls, 1996; Nelson et al, 1972). In the last two decades these claims have been investigated mainly through empirical mode comparisons of computerized and paper-and-pen versions of the same questionnaire. These studies mainly focus on data quality, only few studies also investigate costs. In the remainder of this paper I will concentrate on data quality.

I start with a model for the influence of computer assisted interviewing, discriminating between technological and methodological data quality. I will proceed with a short overview of empirical evidence for technological data quality, timeliness and cost reduction. I will then focus on methodological data quality: what happens in the interview situation and how it influences data quality. Since acceptance of computer-assisted methods is an important criterion by itself, I 
also include research on the attitudes and opinions of interviewers and respondents. I end with a discussion on the challenges that new emerging technologies offer.

\section{Survey data quality and computer-assisted interviewing}

As early as 1972, Nelson, Peyton, and Bortner pointed out that automatic routing to the next question and range checks on the given answers would enhance data quality. They emphasize technological or operational data quality: the reduction of previously required post interview data processing activities (Nicholls, 1996). Operational data quality is affected by all the technological possibilities of computer assisted interviewing.

Factors associated with the visible presence of a computer and its effect on the interview situation may affect data quality, apart from the technical aspects. These factors affect methodological data quality, defined by an absence of nonsampling survey bias and error (Nicholls, 1996; cf. Groves, 1989).

Recently, Total Quality Management (TQM, Deming, 1982) has received much attention in industrial settings and in a lesser degree in statistical and survey establishments. As a consequence, additional criteria for 'good' data collection methods have been formulated. The most important are timeliness and costs: does a new technology provide the data more quickly and does it reduce the costs? (Blyth, 1998).

\subsection{Potential for improving technological data quality}

Compared to an optimally implemented paper-and-pencil interview, the optimally implemented computer assisted interview has five apparent advantages.

(1) There are no routing errors. If a computer system is correctly programmed, routing errors, that is, errors in the question order, skipping and branching, do not occur. Based on previously given answers the program decides what the next question must be, and so both interviewer and respondent are guided through the questionnaire. Missing data because of routing and skipping errors does not occur. Also, questions that do not apply to a specific respondent are automatically skipped. As a result, automatic routing reduces the number of data errors.

(2) Data can be checked immediately. An optimally implemented interview program will perform some internal validity checks. The simplest checks are range checks that compare the given response to the range of possible responses. Thus the program will refuse the response ' 8 ' to a seven-category Likert scale, and then ask to correct the response. Range checks are straightforward when the question has only a limited number of response categories. More complicated checks analyze the internal consistency of several responses. Consistency checks are more difficult to implement; one must anticipate all valid responses to questions, list possible inconsistencies, and devise a strategy for the program to cope with them. In a paper-and-pencil study, internal validity checks have to be conducted at the data cleaning stage that usually follows the data collection stage. However, when errors are detected, they can only be recoded to a missing data code because it is no longer possible to ask the respondents what they really meant. During a computer-assisted interview there is an opportunity to rephrase the question and correct range and consistency errors. This should lead to fewer data entry errors and missing data.

(3) The computer offers new possibilities to formulate questions. One example is the possibility to randomize the order of questions in a scale, giving each respondent a unique question order. This will eliminate systematic question order effects. Response categories can 
also be randomized, which avoids question format effects (e.g., recency effects). The computer can also assist in the interactive field coding of open questions using elaborate coding schemes, which would be unmanageable without a computer. Finally, the computer can be used to employ question formats such as drawing line lengths as in psychophysical scaling, and other forms of visual aids, which in paper and pencil methods are more awkward to use.

(4) There is no separate data entry phase. This means that no extra errors are added. It also implies that the first tabled results can be available soon after the data collection phase. On the other hand, construction, programming, and checking of the questionnaire take considerable time in computer-assisted data collection. Thus, a well-planned computer-assisted survey has a real advantage when the results must be quickly available right after data collection (as in election forecasts).

\subsection{Potential for improving methodological data quality}

The visible presence of a computer may affect data quality, apart from the technical aspects of using a computer. Both usability (e.g., simple human-computer interface, learning) and psychological factors can play a role. As with most technological innovations the effects are for the most part temporary. After some time, one gets used to the new machine, and its influence on the situation becomes smaller. In the early days, even in the USA, one of the early adapters to technological innovations, in 1997 only around 45\% of the households had computers and the proportion with Internet access was around 22\% (cf. Witt, 1997). But these numbers have increased rapidly. In 1998, the US Bureau of the Census estimated that $26 \%$ of the households used Internet at home, and the percentage of persons using internet (inside and outside the home) was estimated at $33 \%$ or a third of the adult population of 18 years and older, which corresponds to 65 million US adults (Couper, 2000). But the picture differs from country to country; although Internet access is still growing and now around $70 \%$ of the US population has access to the net, the picture is diverse with percentages ranging from $76 \%$ coverage for Sweden to 3.6\% in Africa (www.internetworldstats.com, data from August 2007).

Compared to traditional paper and pencil methods, the presence of a computer could lead to the following effects (positive and negative) on how the whole data collection procedure is perceived.

(1) Less privacy. When one is totally unfamiliar with computers there could be a 'big brother' effect, leading to more refusals and socially desirable answers to sensitive questions. When researchers first started to use computer assisted data collection, this was a much-feared effect.

(2) More privacy. Using a computer could also lead to the expectancy of greater privacy by the respondents; responses are typed directly into the computer and cannot be read by anyone who happens to find the questionnaire. Much depends here on the total interview situation and how the survey is implemented.

(3) Trained interviewers may feel more self-confident using a computer, and behave more professionally. This in turn could lead to more confidence and trust of the respondent in the interviewing procedure as a whole.

(4) The knowledge that the system accurately records information about the interview process itself (e.g., time and duration of the interview, the interval between interviews and the order in which they are carried out) inhibits interviewers to 'cheat'.

(5) The use of a computer may distract interviewers. They have to pay attention to using the computer correctly and typing in the answers accurately. If interviewers cannot touch-type, typing in long answers may lead to less eye contact between interviewers and respondents, causing the interviewers to miss nonverbal reactions of the respondents. If the computer is 
located between the interviewer and the respondent, even the physical distance may be greater than in a paper and pen interview. These factors all weaken the 'rapport' between interviewer and respondent; as a consequence the interview may not be conducted optimally, and data quality may suffer.

(6) On the other hand, a well-trained and experienced interviewer can rely on the computer for routing and complex question sequences, and therefore pay more attention to the respondent and the social processes involved in interviewing.

\subsection{Potential for increased timeliness and reduced costs}

Going from paper-and-pencil to computer assisted interviewing asks for initial investment, not only in equipment, but also in time. One has to invest in hardware, software and in acquiring hardware- and software-related knowledge and skills. In addition, basic interviewer training now needs to include training in handling a computer and using the interviewing software.

After the initial investments are made, a computer-assisted survey may be less costly and quicker than traditional data collection, but it all depends on the study: its complexity, its size, and its questionnaire. To evaluate the cost efficiency and timeliness of a computer assisted survey, a distinction should be made between front-end processing and back-end processing. In general, a well-designed computer assisted survey requires investing more time, effort, and money in the beginning of the research (front-end processing), which is saved at the end stage (back-end processing). Especially the design and implementation of range and consistency checks (front-end) reduces the time needed to prepare the data for the analysis (back-end); and no questionnaires have to be printed, entered, or coded.

\section{Empirical evidence for improved quality: technological data quality, timeliness and cost.}

\subsection{Technological data quality}

Technological data quality was defined above as the reduction of previously required post interview data processing activities. Using a well-programmed and tested interview program can reduce the number of errors in the data by preventing mistakes (cf. section 2.1). Empirical studies confirm this expectation.

Computer Assisted Telephone Interviewing (CATI).

In their review Groves and Nicholls (1986) conclude that CATI leads to less missing data because it prevents routing errors. For instance, Groves \& Mathiowetz (1984) found five times more skip errors in paper telephone surveys then in CATI. It is not therefore not surprising, that post hoc data cleaning finds more errors with traditional paper-and-pencil methods than with CATI. However, no difference is found in respondent induced missing data (i.e., 'do-not-know' and 'no-answer' responses). The same conclusions are drawn by Weeks (1992), Martin and Manners (1995), and Nicholls, et al (1997).

In addition, Catlin and Ingram (1988) studied the possible effects of computer use on open questions; they found no differences between computer assisted and paper interviewing in codability of answers to open questions or length of answers (number of words used). See also Kennedy et al (1990).

Computer Assisted Personal Interviewing (CAPI)

The percentage of missing data is clearly lower in CAPI, mostly because interviewers cannot 
make routing errors (Sebestik, Zelon, DeWitt, O'Reilly \& McCowan, 1988; Olsen, 1992). Bradburn et al. (1992) found in a pilot CAPI study that the number of missing data caused by respondents ('do-not-know', 'no-answer') also diminishes, but in the main study this was not replicated (Baker \& Bradburn, 1992; Olsen, 1992). Other studies also fail to find a difference in respondent induced missing data (Bemelmans-Spork, Kerssemakers, Sikkel \& Van Sintmaartensdijk, 1985; Martin, et al., 1994).

Little is known about data quality regarding open questions. Baker (1992) summarizes a study by the French National Institute for Statistical and Economical Research (INSEE) that did not find any difference between PAPI and CAPI in this respect.

\section{Computer Assisted Self Interviewing (CASI, CSAQ)}

Computer Assisted Self Administered Questionnaires (CSAQ) and Computer Assisted Self Interviewing (CASI) make it possible to use very complex questionnaires without the aid of an interviewer. But also in standard, less complex self-administered questionnaires, CASI reduces item nonresponse (see Ramos, et al, 1998). In a well-designed and thoroughly tested computer questionnaire, it is not possible for a respondent to skip a question by mistake. This is clearly illustrated by the findings of Van Hattum \& De Leeuw (1999). They used computer assisted self administered questionnaires in primary schools and compared data from paper and pencil (PAPI) self administered questionnaires with data from computer assisted self administered questionnaires (CSAQ). In the CSAQ-condition the mean percentage of missing values was $5.7 \%$ (standard deviation $=3.4 \%$ ), while in the PAPI-condition the mean of the percentage missing values was $14.1 \%$ (standard deviation $=25.0 \%$ ). It is interesting to note that not only the average amount of missing data is less in computer assisted data collection, but also that the individual differences, indicated by the standard deviation, are smaller. Van Hattum \& De Leeuw (1999) attribute this to the fact that with a paper questionnaire children who are not concentrating on the task or who are careless can easily skip a question or even a whole page by mistake, while CSAQ forces children to be more precise.

A small number of studies have explicitly compared respondent entry errors in computerized versus paper and pen questionnaires. Fewer respondent errors are reported in CASI than in paper and pen self-administered questionnaires. For an overview, see Nicholls et al (1997).

\subsection{Timeliness and costs}

A distinction should be made between front-end processing and back-end processing (cf. 2.3). In general, front-end processing (i.e., developing, implementing and testing the questionnaire) takes more time and is therefore more expensive. On the other hand, no data-entry is needed and data editing and data cleaning take less time: back-end processing is faster. With very large surveys this will save time. In general, there is no difference in the total time needed for the research. But once the interviewing has started, results are available much faster than in traditional paper-and-pencil interviewing. Samuels (1994) mentions a reduction of delivery time of $50 \%$ for the results of an omnibus survey. When timeliness and a fast release of results are important for a client, this is an important advantage of computer-assisted data collection over paper-and-pencil methods. During interviewing, time may be saved by the improved efficiency of computer assisted sample management (Nicholls \& De Leeuw, 1996).

\section{Computer Assisted Telephone Interviewing (CATI).}

Most studies that attempt to weigh the costs and advantages of CATI conclude that the initial investments in hardware and software pay off only for large scale or regularly repeated surveys 
(Groves \& Tortora, 1998). A rule of thumb is that the break-even point is at about thousand telephone interviews. Below that number, the argument of cost reduction is, by itself not sufficient to use CATI (Weeks, 1992).

\section{Computer Assisted Personal Interviewing (CAPI)}

CAPI requires a larger investment in hardware, software and support staff than CATI (Blyth, 1998). These high fixed costs are only compensated by lower flexible costs (e.g. saving in printing cost, data-entry, and editing) for large scale surveys. Bond (1991) states that even when computers are used frequently in the fieldwork it will take at least a year before the investment starts to pay back.

There is limited empirical data on cost comparisons between computer assisted and paper and pencil personal interviews. Two studies systematically assess costs for CAPI: initial investment in hardware and software was excluded, but extra fieldwork costs for training and supervision were included. Sebestik et al. (1988) compared costs in a small scale CAPI experiment. Their conclusion is that overall CAPI was more expensive, mostly because of added costs in training and supervising interviewers. In a larger experiment Baker and Bradburn (1992) conclude that CAPI was still more expensive $( \pm 12 \%)$ than PAPI; the cost reduction in entering and cleaning data was not large enough to offset the higher training and supervision costs. Baker (1990) extrapolates these findings and concludes that when fixed hardware costs are excluded, approximately 1500 CAPI interviews are needed to reach the break-even point between increased front-end and decreased back-end costs.

\section{Computer Assisted Self Interviewing (CASI, CSAQ)}

Computer assisted self-administered questionnaires (CSAQ) and Disk-by-Mail and e-mail surveys have the advantage that no interviewers are needed, so in comparison with CATI and CAPI they save costs. This is one of the main reasons why Baker (1998) predicts a decline of interviewing and a rise of CASI and $\mathrm{CSAQ}^{2}$. When one compares computer assisted procedures with the traditional paper mail survey cost savings are not so obvious. As with all forms of computer assisted data collection, the extra investment in programming the questionnaire and debugging only pays off for large surveys where printing and editing make the paper form more costly (cf. Ramos, et al, 1998). In Disk-by-Mail, the mailing costs include a special protective envelope. Also, a disk is heavier than a short paper questionnaire, which makes DBM in generally somewhat more costly than paper mail questionnaires (Saltzman, 1992). However, when large numbers of longer questionnaires have to be mailed, DBM can be a real cost saver. Van Hattum and De Leeuw (1999) systematically compare costs for a DBM and a paper mail survey of 6000 pupils in primary schools. They conclude that the average cost for a completed questionnaire is 1.01 US dollars for a Disk-by-Mail survey and 3.22 US dollars for a paper-andpen mail survey.

E-mail and web surveys pose an extra challenge for Europe. Clayton and Werking (1998) describe the cost savings (e.g., labour, postage) in a e-mail survey of businesses. Transmission costs (telephone) are practically zero. However, unlike the USA, in most European countries local telephone calls are not free! This not only increases the costs for the researcher, but also increases the costs (internet connect time both receiving and sending) for the potential respondent. To ensure high response rates, one has to find ways to reduce respondent costs comparable to prepaid return postage in mail surveys, or reimburse factual costs. In panel surveys (e.g., Saris, 1998), the research organization usually reimburses costs and gives

\footnotetext{
${ }^{2}$ One of the major problems with e-mail surveys and Disk by Mail is still coverage. For a successful application, one is restricted to surveying special groups. Another possibility is a multimode approach (cf Schaeffer \& Dillman, 1999, De Leeuw, 2005).
} 
additional incentives.

\section{Empirical evidence for improved quality: acceptance of new technology and methodological data quality.}

\subsection{Acceptance of new technology}

The use of a computer may have an influence on the behaviour of both interviewer and respondent. Therefore, in the first applications of computer assisted interviewing special attention was paid to the acceptance of the new technology.

\section{Acceptance by interviewers CATI and CAPI}

In the early days, when systems were slow and portable computers heavy, interviewer acceptance was not general. Acceptance depended strongly on the speed and reliability of systems (Nicholls et al, 1997; De Leeuw et al, 1998). With modern systems acceptance is high (Weeks, 1992). Well-trained interviewers are positive about computer-assisted interviewing. They appreciate the support that a good system offers when complex questionnaires are employed (Riede \& Dorn, 1991; Edwards, Bittner, Sherman Edwards \& Sperry, 1993), they like working with the computer (Martin et al., 1994), and derive a feeling of professionalism from it (Edwards et al., 1993). However, crucial for acceptance is that interviewers are well-trained in general computer skills, in the specific computer assisted interview system that is used, and in general interviewing techniques (cf. Woijcik \& Hunt, 1998). Besides training, ergonomic factors are of influence too: readability of screens, well-defined function keys, and usability, are important factors for acceptance (De Leeuw \& Nicholls, 1996; Couper et al, 1997). In addition, a good human-computer interface may contribute to the avoidance of human errors.

\section{Acceptance by respondents and unit nonresponse: CATI and CAPI}

In telephone interviews, respondents as a rule will not notice whether a computer is used or not, it is not surprising that no differences in unit nonresponse are found between CATI and traditional paper and pen telephone interviews (cf. Nicholls et al. 1997, De Leeuw et al., 1998). When computer assisted personal interviewing was introduced researchers were afraid of a negative effect on response rates. But even in the first applications of the method in Sweden and the Netherlands this did not occur (Van Bastelaer, Kerssemakers \& Sikkel, 1987, p 39; Van Bastelaer et al., 1988). Later studies confirm that CAPI and paper-and-pencil methods yield comparable response rates in studies in the U.S.A. (Bradburn, Frankel, Baker \& Pergamit, 1992; Sperry, Bittner \& Brandon, 1991; Thornberry, Rowe \& Biggar, 1991), England (Martin, O'Muircheartaigh \& Curtice, 1994), Sweden (Statistics Sweden, 1989) and Germany (Riede \& Dorn, 1991). These studies also report very low percentages of spontaneous negative reactions by respondents (1-4\%). Most reactions are neutral or positive.

When respondents are explicitly asked for a reaction to using the computer they generally react positively and are found to prefer (Woijcik \& Baker, 1992). Baker $(1990,1992)$ reports that most respondents find CAPI interesting, and attribute a greater degree of professionalism to CAPI. The social interaction with the interviewer is generally described as comfortable and relaxed. Only a small percentage (5\%) reports negative feelings. 
the respondents ${ }^{3}$; they evaluate it positively and find it interesting and easy to use (for overviews see Ramos et al, 1998; De Leeuw et al, 1998). Beckenbach (1995) reports that more than $80 \%$ of the respondents had no problem at all using the computer or the interviewing program, and that few respondents complained about physical problems such as eye-strain.

The general positive appreciation also shows in the relative high response ratio with Disk By Mail (DBM) surveys. DBM response rates in market research vary between $25 \%$ and $70 \%$, and it is not unusual to have response ratio's of 40 to 50 percent without using any reminders (Saltzman, 1992). Assuming that this is a special population interested in the research topic, an ordinary well conducted mail survey using no reminders may be expected to yield about 35\% response (Dillman, 1978; Heberlein \& Baumgartner, 1978). The high response rates may be partly caused by the novelty value of DBM, which will diminish over time. It should be noted that Ramos et al (1998) found no evidence for higher response rates in DBM in academic and government surveys.

How e-mail or web surveys will develop further remains unsure. The novelty value is wearing of, and electronic junk-mail (SPAM) is increasing fast. Also, one mouse-click is enough to through away anything unwanted or uninteresting. This could lead to extreme low response rates, which would threaten the validity of the conclusions. That nonresponse is a serious problem for Internet surveys is illustrated by Lozar Manfreda et al (2007). In a carefully conducted meta-analysis, they studied 45 empirical comparisons and found that on average web surveys yield an $11 \%$ lower response rate than comparable paper mail and telephone surveys To ensure an acceptable response for e-mail and web surveys one should carefully analyze what electronic surveys different (e.g., security of the net, costs). These issues should be carefully addressed, in doing this we can learn from the past. Many principles that in the past have proved to be successful in paper mail surveys, can be successfully translated to electronic surveys (De Leeuw, 1997; Schaeffer \& Dillman, 1999; Dillman, 2000). But, we have to go one step further, we must learn to optimally use the enormous audio-visual potential of this new medium (Couper, 2000).

There are promising results from panel-surveys, which use Internet. In the Netherlands at Tilburg University, general population household panels are now completely operating through Internet. Of course, panel members received instruction in how to use the new technology, a help-desk is available, and all costs are reimbursed (Centerdata: www.centerdata.nl). In the USA Knowledge networks works along the same principles. These panels have in general high response rates on individual surveys. Of course, what one should keep in mind is that the most crucial stage in longitudinal research is the recruitment stage, where candidates for panel membership may fail to participate for a variety of reasons. If this initial nonresponse is taken into account, response is low (Sikkel, Hox, de Leeuw, 2008).

\subsection{Methodological data quality}

\section{Computer Assisted Telephone Interviews (CATI)}

In telephone interviews the computer is not visible present. Respondents may occasionally hear keyboard clicks, or be told by the interviewers that a computer is used. No systematic research has been done on the effects of this knowledge, but the general impression is that it makes no difference to respondents if they know that their answers are typed directly into a computer (Catlin \& Ingram, 1988; Groves \& Nicholls, 1986; Weeks, 1992). It is therefore not surprising

\footnotetext{
${ }^{3}$ One should note that CSAQ/CASI is restricted to special populations. As a consequence, research is based on selected populations, which either had access to computers, or received a computer for the duration of the study (e.g. De Leeuw, Hox, Kef, 2003).
} 
that there are no indications for any differences in methodological data quality between computer assisted and paper and pen telephone interviews. CATI does lead to less missing data because it prevents routing errors, but there is no difference in respondent induced missing data because of 'don't know' and 'no answer' responses. Also, no differences in 'openness' or social desirability are found (Groves \& Nicholls, 1986; Weeks, 1992).

Interviewers, however, know that a computer system is used, and that more rigid control takes place. Computer assisted interviewing often leads to a greater standardization of the interview, to the extent that interviewers sometimes complain about 'rigidity' (Riede \& Dorn, 1991, p 51). In general, researchers appreciate this greater standardization because this minimizes interviewer bias (Fowler, 1991). There is some confirmation of greater standardization of interviewer behaviour in CATI: in a controlled comparative study, using the same interviewers both for traditional and for computer assisted interviews, Groves and Mathiowetz (1984) found less interviewer variance in CATI than in the paper-and-pencil method.

\section{Computer Assisted Personal Interviewing (CAPI)}

In face-to-face interviews the computer is highly visible and respondents may react to its presence. This could influence respondents' trust in the privacy of the data. When researchers first started to use CAPI, they feared a 'big brother' effect, leading to more refusals and socially desirable answers to sensitive questions. An alternative hypothesis was that the use of a computer could also lead to feelings of greater privacy by the respondents; responses are typed directly into the computer and cannot be read by anyone who happens to find the questionnaire. There is no hard empirical evidence for either hypothesis. The acceptance of computer assisted face-to-face interviewing is high for both respondents and interviewers, and there are no indications that using a computer disturbs the interviewing situation (Beckenbach, 1992).

Bradburn et al. (1992) found in a pilot CAPI study that the amount of missing data explicitly caused by respondents ('do-not-know', 'no-answer') also diminished, but in the main study this is not replicated (Baker \& Bradburn, 1992; Olsen, 1992). Other studies also fail to find a difference in respondent induced missing data (Bemelmans-Spork, Kerssemakers, Sikkel \& Van Sintmaartensdijk, 1985; Martin, et al., 1994).

An early and much cited comparative study by Waterton (1984, see also Waterton \& Duffy, 1984) reports a positive effect of CAPI with a sensitive question about alcohol consumption; using the CAPI method more alcohol consumption was reported, which means that presumably CAPI was less affected by social desirability bias. However, in the CAPI mode the sensitive question was asked by letting the respondent type their own answers into the computer, unseen by the interviewers, which makes this part of the interview like a selfadministered questionnaire (CASI). In the traditional paper and pen mode, the question was asked by the interviewer and the answer was taken down by the interviewer. Since selfadministered questionnaires typically show less social desirability bias than face-to-face interviews (for an overview, see De Leeuw, 1992), the reported difference between PAPI and CAPI in this study may well correspond to a difference between an interview and a selfadministered questionnaire, and not to a technology effect.

Studies that do compare paper and pen face-to-face interviewing and computer assisted personal interviewing and therefore focus on the effect of the new technology more purely, do report slightly less social desirability bias with CAPI (Baker \& Bradburn, 1992; Bradburn et al., 1992; Martin et al., 1994; Tourangeau \& Smith, 1998). However, the differences are very small, generally being smaller than differences typically found in comparisons of face to face versus telephone interviews or experienced versus inexperienced interviewers (Olsen, 1992). Tourangeau and Smith (1998) also found an interesting interaction with location of interview. 
When the interview took place in the respondent's home, the computer assisted version produced more 'openness' in answers. However, when interviewed outside the home in a health clinic, fewer open answers were given and the computer assisted version revealed fewer sex partners than the paper and pen version. This suggests that setting is important. It is probably more the way respondents perceive the total (computer assisted) interview situation, than the use of the computer itself, that influences methodological data quality.

\section{Computer Assisted Self Interviewing (CASI, CSAQ, Web)}

There is strong evidence that for paper-and-pen modes, self-administered questionnaires are better at eliciting sensitive information than interviews (for an overview, see De Leeuw, 1992; De Leeuw \& Collins, 1997). Computer-assisted self-interviewing has the additional advantage that complex questionnaires with many routings (e.g., health inventories) can now be administered in self-administered form. Whether a computer-assisted form also will produce more open answers and more self-disclosure than a paper and pen questionnaire has been the topic of a number of studies.

Several studies showed more self-disclosure on sensitive topics (e.g., abortion, malemale sexual contact) when using CASI (cf. Turner, et al., 1998; Tourangeau \& Smith, 1998). There is some evidence that the use of Audio-CASI does not chance this effect (Turner et al., 1998; O'Reilly,et al., 1994). In a meta-analysis of 39 studies, Weisband and Kiesler (1996) found a strong significant effect in favor of computer methods. This effect was stronger for comparisons between CASI and face-to-face interviews. But, even when CASI was compared with self-administered paper-and-pen questionnaires, self-disclosure was significantly higher in the computer condition. The effect reported was larger when more sensitive information was asked. Weisband and Kiesler (1996) also report the interesting finding that the effect is diminishing over the years, although it has not disappeared! They attribute the diminishing effect to a growing familiarity with computers and their possibilities among the general public. Interestingly, their meta-analysis also showed that the data were not homogeneous. This means that although the general trend was in favor of computer assisted methods, some studies showed the opposite effect.

Recent research suggests that these contradictory findings could be attributed to the interview situation and perceived privacy. For instance, Van Hattum \& De Leeuw (1999) compared CASI and paper self-administered questionnaires in a study on bullying at primary schools. They reported more openness and less social desirability in the CASI condition. In their study, pupils worked at the class computer, in a special room or a quiet secluded corner of the class. The paper questionnaires were administered in the classroom, where care was taken that pupils could not see each other's answers. Beebe et al (1998) investigated illicit drug use among young high school students. They compared in-class self-administered paper tests which were placed in an envelope with computer assisted questionnaires that were administered in the computer lab. In this study, the paper self-administered test produced more openness in the reporting of sensitive behavior. However, further analyses showed that the distance between computer stations in the lab was crucial. For those students who were more than five feet away from each other in the computer lab, the answers were very similar to the answers of the students who used a paper questionnaire. These two studies underscore the extreme importance of perceived confidentiality.

When using computer assisted questionnaires one should take careful precautions to gain respondents' trust. The setting and the implementation of the questionnaire should reassure the respondent about confidentiality. Simple precautions, like masking the answer or refreshing the screen when the answer has been given, will probably do the trick. Also, whenever, other persons are in the same room - be it interviewers, family members, teachers, or other students in a lab - they should be kept at some distance. 
Internet surveys are self-administered, so there is no interviewer present to assist the respondent when difficulties arise. Internet surveys are by definition computer-assisted and share all the advantages of computer-assisted surveys, which means that complex questionnaires with controlled routing (skipping and branching) can be used. Empirical research on the quality of web surveys is still scarce, although the number of studies is growing rapidly. There is some indication that Internet surveys are more like mail than like telephone surveys, with more extreme answers in telephone surveys than in Internet surveys (Dillman,

Phelps, Tortora, Swift, Kohrell, and Beck, 2001; Oosterveld and Willems, 2003). More extremeness in telephone interviews was earlier found in comparisons with paper mail surveys and is attributed to visual versus auditive information transmission (De Leeuw, 1992; Schwartz et al 1991); the same mechanism may be responsible for differences between telephone and Internet surveys. Comparisons between web and mail surveys give mixed results, some studies find more partial response and more item nonresponse in web surveys (Lozar Manfreda, Vehovar, and Batagelj, 2001; Bates, 2001), others report less item nonresponse in web surveys than in mail surveys (McMahon, et al, 2003; Beullens, 2003). Regarding substantive responses no clear picture emerges; Oosterveld and Willems (2003) found little to no differences between CATI and Internet in a well-controlled experiment. Beullens (2003) reported some differences, but when he controlled for differences in background characteristics due to self-selection, the differences between mail and web are negligible. However, Link and Mockdad (2005) did find differences in alcohol reporting and other health related estimates between web and mail surveys, and Bäckström and Nilsen (2004) reported differences in substantive answers between paper and web questionnaires in a student evaluation survey.

Trust is an important aspect in web surveys, as is illustrated by study in Japan, which emphasizes the importance of mutual trust for (non)response and data quality (Yoshimura \& Ohsumi, 2000). In an early study Kiesler and Sproull (1986) found fewer socially desirable answers in an electronic questionnaire than in the paper mail version. Subsequent studies (Mitchell, 1993) found no differences. Extrapolating the findings summarized above on both CASI and internet surveys, I suggest that in e-mail and web surveys privacy and security could be crucial factors when asking for sensitive information. Respondents should have the feeling that their answers are safe, and encryption in combination with an icon to convey the message (e.g., a key) should be standard. When designing special surveys, we should focus more on the human-computer interaction and the perceptions and reactions of the respondent. In the end it is the respondent not the technology that matters (cf. Blyth, 1998)

\section{Summary}

Computer assisted telephone interviewing and computer assisted face-to-face interviewing, are by now widely used in survey research. Computer-assisted self-interviewing is gaining in popularity, especially through web surveys and Internet panels.

Computer assisted data collection has a high potential to improve data quality. This together with the expectations that it would also improve efficiency and reduce costs, was why computer assisted data collection has become popular so quickly. However, for most of these potential advantages the empirical evidence is still limited. Systematic comparisons of costs and efficiency are rare, and the evidence for cost and time reduction is not very strong. A well designed-computer assisted survey requires investing more time, money, and effort in the beginning of the process (front-end processing), which is saved at the end stage (back-end processing. These investments will only pay off in large scale or regularly repeated surveys.

There is little evidence that the use of CAPI, CATI and Disk-by-Mail surveys improves 
response rates. Conversely, there is also no evidence for a decrease in response rates. How email and web surveys will develop remains uncertain. The novelty value is wearing off and electronic junk mail is increasing. In addition, there may be financial costs (telephone costs and connect time for most European countries). To ensure an acceptable response and good data quality, one should carefully analyse what makes web surveys different (e.g., security, access to the net of different demographic groups, connect costs, influence of screen lay-out on measurement error and the robustness of lay-out for different web-browsers), and address these issues in the design of the survey.

Internet surveys are fast and have low cost. Being self-administered there are no interviewer effects, although the use of pictures and visual illustrations may influence respondents answers. The largest problems in Internet surveys are coverage and nonresponse. Often, the sample in a Web survey is not a probability sample from a general population, and there is no good method for generating random samples of email addresses. In addition, measurement problems arise because questionnaires may look different in different browsers and on different monitors, and respondents may have different levels of computer expertise.

There is ample empirical research of improved technological data quality in computerassisted data collection. A well-programmed and tested interview program will have range and consistency checks, and prevent routing errors, which results in far less item nonresponse. Computer assisted data collection is no panacea for good data quality. It requires one to do almost everything that is needed with a good paper-and-pen interview or questionnaire, and to add extra effort in computer implementation, in testing the questionnaire, in designing an ergonomic screen lay-out, in extra interviewer training, and in designing a respondent friendly and trustworthy questionnaire. However, this investment is earned back in far less interviewer error and the error-free administration of complex questionnaires.

There is some evidence that computerized methods of data collection improve methodological data quality. Respondents are less inhibited and show more self-disclosure when sensitive questions are used. But this effect may be diminishing over time, as some studies suggest. Also, there is evidence that much depends on the perception of the interview situation by the respondent and on careful design of the total study and of the computer interface.

\section{Discussion}

Computer assisted data collection has a high potential to increase timeliness of results, improve data quality, and reduce costs in large surveys. However, for most of these potential advantages the empirical evidence is still limited. The majority of studies investigate the acceptability by respondents and some aspects of data quality. A systematic comparison of costs is difficult, and consequently these are rare. When the total costs of paper-and-pencil and computer assisted survey research are compared, the evidence for cost reduction is not very strong. The investments will only pay off in large scale or regularly repeated surveys.

At present, there is ample empirical research of improved technological data quality in computer-assisted data collection. A well-programmed and tested interview program will have range and consistency checks, and prevent routing errors, which results in far less item nonresponse. However, computer assisted data collection is not being used to its full potential, and the various aspects of data quality that have been studied are too limited (cf. Sikkel, 1998). The strength of computer assisted data collection methods is the ability to increase the power of interviewing and thus to answer more complex research questions. We should explore the potential of the computer and use techniques for data collection that are impossible or impractical with paper and pencil methods. For instance, randomization of question order and randomization of the order of response categories can be implemented to avoid well-known 
order effects. Also, with the aid of computer assisted interviewing very complex questions can be asked and continuous response scales can be used in 'standard' interview situations (e.g., computerized diaries, vignettes, magnitude estimation). Measurement techniques that would be almost impossible to use without a computer are natural grouping, adaptive conjoint analysis, and tailored or controlled dependent interviewing (Sikkel, 1998; De Leeuw et al, 1998).

There is little evidence that CATI or CAPI improve response rates. Conversely, there is also no evidence for a decrease in response rates. In general, both interviewers and respondents evaluate computer assisted interviewing positively, and CAI is accepted without problems. However, interviewers should be well trained and experienced and much depends on the interview situation. Computer assisted interviewing makes it possible to supervise interviewers more closely and study interviewer behaviour by analyzing computer files. However, comparative research has paid little attention to the effect of computerization on interviewer variance and other aspects of interviewer behaviour (exceptions are Groves \& Mathiowetz, 1984; Couper, et al., 1998).

There is some evidence that computerized methods of data collection improve methodological data quality. Respondents are less inhibited and show more self-disclosure when sensitive questions are used. But this effect may be diminishing over time, as some studies suggest. Furthermore, there is evidence that much depends on the perception of the interview situation by the respondent and on careful design of the total study and of the computer interface. For instance, the distance between computers in a computer lab influences the openness on answers; a larger distance gives more openness. Also, whether or not the typed-in answers remain on the screen or are 'masked', and whether sounds come over a head phone or through speakers in computer assisted self-interviews may affect answers on sensitive questions.

Systematic research on these topics will teach us more about how to use computers optimally in data collection. In doing this, we should keep in mind that it is the human that counts not the technology. How respondents perceive the interview situation, how large their (mis)trust in computers is and how much they trust the survey organization, will determine the success of computer-assisted method and especially of web surveys.

Finally, I should emphasize that computer assisted data collection is no panacea for good data quality. It requires one to do almost everything that is needed with a good paper-and-pen interview or questionnaire, and to add extra effort in computer implementation, in testing the questionnaire, in designing an ergonomic screen lay-out, in extra interviewer training, and in designing a respondent friendly and trustworthy questionnaire. However, this investment is earned back in far less interviewer error and the error-free administration of complex questionnaires. It also offers us the opportunity to use really complicated questionnaires with complex routing patterns, without the help of an interviewer (cf. Saris, 1998). If special efforts during the implementation are made and if the new possibilities computers offer us are really used, we have the opportunity for obtaining not only better data, but clearly superior data with computers. We should therefore use computer assisted data quality to its full potential and invest in the development of new applications. In every survey the available tools do effect the type of questions we can ask, and computer assisted data collection is offering us a large and sophisticated methodological toolbox indeed. We should use this toolbox wisely!

\section{References}

Baker, R.P. (1990). What we know about CAPI: Its advantages and disadvantages. Paper presented at the annual meeting of the American Association of Public Opinion Research, Lancaster, Pensylvania. 
Baker, R.P. (1992). New technology in survey research: Computer assisted personal interviewing (CAPI). Social Science Computer Review, 10, 145-157.

Baker, R.P. (1998). The CASIC future. In: M.P. Couper, R.P. Baker, J. Bethlehem, C.Z.F. Clark, J. Martin, W.L. Nicholls II, \& J.M. O'Reilly (eds). Computer assisted survey information collection (pp. 583-604). New York: Wiley.

Baker, R.P. \& Bradburn, N.M. (1992). CAPI: Impacts on data quality and survey costs. Information Technology in Survey Research Discussion Paper 10 (also presented at the 1991 Public Health Conference on Records and Statistics).

Bates, N. (2001). Internet versus mail as a data collection methodology from a high coverage population. Proceedings of the Annual Meeting of the American Statistical Association. August 2001.

Beckenbach, A. (1992). Befragung mit dem Computer, Methode der Zukunft?. Anwendungsmöglichkeiten, Perspektiven und experimentelle Untersuchungen zum Einsatz des Computers bei Selbstbefragung und persönlich-mündlichen Interviews. [In German: Computer Assisted Interviewing, A method of the future? An experimental study of the use of a computer by self-administered questionnaires and face to face interviews]. Ph.D. thesis. Universität Mannheim.

Beckenbach, A. (1995). Computer assisted questioning: The new survey methods in the perception of the respondents. BMS, 48, 82-100.

Beebe, T.J., Harrison, P.A., McRae, J.A., Anderson, R.E., \& Fulkerson, J.A. (1998). An evaluation of computer-assisted self interviews in a school setting. Public Opinion Research, 62, 623-632.

Beullens, K. (2003). Evaluatie van een mixed-mode survey design [Evaluation of a mixedmode survey design]. Leuven: Katholiek Universiteit Leuven.

Bemelmans-Spork, M., Kerssemakers, F., Sikkel, D. \& Van Sintmaartensdijk, H. (1985). Verslag van het experiment 'het gebruik van draagbare computers bij persoons en gezinsenquêtes'. Centraal Bureau voor de Statistiek. [In Dutch: Report of an experiment on the use of portable computers in person and household surveys. Netherlands Central Bureau of Statistics]

Blyth, B. (1998). Current and future technology utilization in European market research. In: M.P. Couper, R.P. Baker, J. Bethlehem, C.Z.F. Clark, J. Martin, W.L. Nicholls II, \& J.M. O'Reilly (eds). Computer assisted survey information collection (pp.563-581). New York: Wiley.

Blyth, B. (1998b). Market research and information technology; Application and innovation. Esomar monograph 6 (introduction). Amsterdam: Esomar.

Bond, J (1991). Increasing the value of computer interviewing. Proceedings of the 1991 ESOMAR congress (Trends in data collection and analysis).

Bradburn, N.M., Frankel, M.R., Baker, R.P. \& Pergamit, M.R. (1992). A comparison of CAPI with PAPI in the NLS/Y. Chicago: NORC. Information Technology in Survey Research Discussion Paper 9 (also presented at the 1991 AAPOR-conference, Phoenix, Arizona)

Catlin, G. \& Ingram, S. (1988). The effects of CATI on costs and data quality: A comparison of CATI and paper methods in centralized interviewing. In: R.M. Groves, P.P. Biemer, L.E. Lyberg, J.T. Massey, W.L. Nicholls II \& J. Waksberg (Eds.). Telephone survey methodology (pp.437-456). New York: Wiley.

Clayton, R.L. \& Werking, G.S. (1998). Business surveys of the future: The world wide web as a data collection methodology. In: M.P. Couper, R.P. Baker, J. Bethlehem, C.Z.F. Clark, J. Martin, W.L. Nicholls II, \& J.M. O'Reilly (eds). Computer assisted survey information collection (pp.543-562). New York: Wiley.

Collins, M., Sykes, W., O'Muircheartaigh, C. (1998). Diffusion of technological innovation: Computer assisted data collection in the UK. In: M.P. Couper, R.P. Baker, J. Bethlehem, 
C.Z.F. Clark, J. Martin, W.L. Nicholls II, \& J.M. O'Reilly (eds). Computer assisted survey information collection (pp.23-43). New York: Wiley.

Couper, M.P., Hansen, S.E., \& Sadovsky, S.A. (1997). Evaluating interviewer use of CAPI technology. In: L. Lyberg, P. Biemer, M. Collins, C. Dippo, N. Schwarz, \& D. Trewin (eds). Survey Measurement and Process Quality (pp. 267-285). New York: Wiley.

Couper, M.P., \& Nicholls, W.L.II (1998). The history and development of computer assisted survey information collection methods. In: M.P. Couper, R.P. Baker, J. Bethlehem, C.Z.F. Clark, J. Martin, W.L. Nicholls II, \& J.M. O'Reilly (eds). Computer assisted survey information collection (pp.1-21). New York: Wiley.

Couper, M.P. (2000). Websurveys; the Good, the Bad, and the Ugly. University of Michigan, Institute for Social Research, Survey Methodology Program, Working paper series \# 077.

De Leeuw, E.D. (1992). Data quality in mail, telephone and face to face surveys. Amsterdam: TT-Publikaties.

De Leeuw, E.D. (1997). Comment on K.J. Witt, Best practices in interviewing via the internet. Sawtooth Software Conference Proceedings. Sequim, Wa: Sawtooth Software inc.

De Leeuw, E.D. (2005). To mix or not to mix data collection modes in surveys. Journal of Official Statistics, 21, 5, 233-255 (also available on www.jos.nu.

De Leeuw, E.D. \& Collins, M. (1997). Data collection method and data quality: An overview. L. Lyberg, P. Biemer, M. Collins, C. Dippo, N. Schwarz, \& D. Trewin (eds). Survey Measurement and Process Quality (pp. 199-220). New York: Wiley.

De Leeuw, E.D., \& Hox, J.J.. (2008). Self-Administered Questionnaires. In E.D. de Leeuw, J.J. Hox, \& D.A. Dillman (Eds) International handbook of survey methodology. Psychology Press, Tailor and Francis.

De Leeuw, E., \& Nicholls, W.L. II (1996). Technological innovations in data collection: Acceptance, data quality and cost. Sociological Research Online, Vol 1, no 4, <http:/www.socresonline.org.uk/socresonline/1/4/leeuw.html>

De Leeuw, E., Hox, J., Kef, S., \& Van Hattum, M. (1997). Overcoming the problems of special interviews on sensitive topics: Computer assisted self-interviewing tailored for young children and adolescents. Sawtooth Software Conference Proceedings (pp.1-14), Sequim: WA: Sawtooth

De Leeuw, E.D., Hox, J.J., \& Snijkers, G. (1998). The effect of computer-assisted interviewing on data quality. In: B. Blyth (ed). Market research and information technology; Application and innovation. Esomar monograph 6 (pp.173-198). Amsterdam: Esomar.

De Leeuw, E.D., Nicholls, W.L.II, Andrews, S.H., Mesenbourg, T.L. (2000). The use of old and new data collection methods in establishment surveys. The use of old and new data collection methods in establishment surveys. Proceedings of the $4^{\text {th }}$ International Conference on methodological issues in Official statistics. Stockholm: SCB.

De Leeuw, E., Hox, J., \& Kef, S. (2003). Computer-assisted self-interviewing tailored for special populations and topics. Field Methods, 15, 223-251

Deming,W.E. (1982). Quality, productivity and competitive position. Cambridge, Ma: Massuchusetts Institute of Technology.

Dillman, D.A. (1978). Mail and telephone surveys; The Total Design Method. New York: Wiley.

Dillman, D.A. (2000). Mail and internet surveys; The Tailoredl Design Method. New York: Wiley.

Dillman, D.A. Phelps, G., Tortorra, R., Swift, K., Kohrell, J., and Berck, J. (2001). Response rate and measurement differences in mixed mode surveys: using mail, telephone, interactive voice response and the Internet. Draft paper at homepage of Don Dillman (http://survey.sesrc.wsu.edu/dillman/) accessed 14 April 2005. 
Edwards, B., Bittner, D., Edwards, W.S. \& Sperry, S. (1993). CAPI effects on interviewers: A report from two major surveys. Paper presented at the U.S. Bureau of the Census Annual Research Conference, Washington D.C.

Fowler, F.J. Jr. (1991). Reducing interviewer-related error through interviewer training, supervision, and other means. In: P.P. Biemer, R.M. Groves, L.E. Lyberg, N.A. Mathiowetz \& S.Sudman (Eds). Measurement errors in surveys (pp. 259-278). New York: Wiley.

Groves, R.M. (1989). Survey errors and survey costs. New York. Wiley.

Groves, R.M. \& Mathiowetz, N.A. (1984). Computer assisted telephone interviewing: Effects on interviewers and respondents. Public Opinion Quarterly, 48, 356-369.

Groves, R.M. \& Nicholls, W.L. II (1986). The status of computer-assisted telephone interviewing: Part II-Data quality issues. Journal of Official Statistics, 2, 117-134.

Heberlein, T.A. \& Baumgartner, R. (1978). Factors affecting response rates to mailed questionnaires; A quantitative analysis of the published literature. American Sociological Review, 43, 447-462.

Johnston, J. \& Walton, C. (1995). Reducing response effects for sensitive questions: A computer assisted self interview with audio, Social Science Computer Review, 13, 304-319.

Kiesler, S. \& Sproull, L.S. (1986). Response effects in electronic surveys. Public Opinion Quarterly, 50, 402-413.

Kennedy, J.M., Lengacher, J.E., \& Demerath, L. (1990). Interviewer entry error in CATI interviews. Paper presented at the International conference on measurement errors in surveys, Tucson, Arizona, 1990.

Lozar Manfreda, K., Bosjnak, M., Berzelak, J., Haas, I., \& Vehovar, V. (2007). Web surveys vs other survey modes: A meta-analysis comparing response rates. International Journal of Market Research

Lozar Manfreda, K., \& Vehovar, V. (2008). Internet Surveys. In E.D. de Leeuw, J.J. Hox, \& D.A. Dillman (Eds) International handbook of survey methodology. Psychology Press, Tailor and Francis.

Lozar Manfreda, K., Vehovar, V., Batagelj, Z. (2001). Web versus mail questionnaire for an institutional survey. In A Westlake et al. The Challenge of the Internet. Association for Survey Computing.

Martin, J. \& Manners, T. (1995). Computer assisted personal interviewing in survey research. In: R.M. Lee (Ed). Information technology for the social scientists. London: UCL Press.

Martin, J., O'Muircheartaigh, C. \& Curtice, J. (1994). The use of CAPI for attitude surveys: An experimental comparison with traditional methods. Journal of Official Statistics, 9, 641661.

Mitchell, D.L. (1993). a multivariate analysis of the effects of gender and computer vs papi modes of administration on survey results. Louisiana Tech University.

McMahon, S.R., Iwamoto, M., Massoudi, M.S., Yusuf, H.R., Stevenson, J.M., Davod, F., Chu, S.Y., and Pickering, L.K. (2003). Comparison of e-mail, fax, and postal surveys of pediatricians. Pediatrics, 111, 4, e299-303

Nelson, R.O., Peyton, B.L. \& Bortner, B.Z. (1972). Use of an online interactive system: Its effects on speed, accuracy, and costs of survey results, paper presented at the 18th ARF conference, New York, november 1972.

Nicholls, W.L. II, Baker, R.P., \& Martin, J. (1997). The effect of new data collection technologies on survey data quality. In: L. Lyberg, P. Biemer, M. Collins, C. Dippo, N. Schwarz, \& D. Trewin (eds). Survey Measurement and Process Quality (pp.221-248). New York: Wiley.

Nicholls, W.L. II, \& De Leeuw, E.D. (1996). Factors in acceptance of computer assisted interviewing methods: A conceptual and historical review. Proceedings of the section of 
survey research methods. American Statistical Association (pp. 758-763).

Nicholls, W.L. II (1996). Definition and assessment of survey data quality in measuring the effects of new data collection technologies. WAPOR-conference, 1996; published in a abbreviated form in: Bulletin of the International Statistical Institute, proceedings of the 51st session (Istanbul), tome LVII, Book 1, 507-510.

Olsen, R.J. (1992). The effects of computer assisted interviewing on data quality. Paper presented at the fourth Social Science Methodology conference, Trento.

Oosterveld P. and Willems, P. (2003). Two modalities, one answer? Combining Internet and CATI surveys effectively in market research. In D.S. Fellows. Technovate. Amsterdam: ESOMAR.

O'Reilly, J.M., Hubbard, M., Lessler, J., Biemer, P.P., \& Turner, C.F. (1994). Audio Computer Assisted Self-Interviewing: New Technology for data collection on sensitive issues and special populations. Journal of Official Statistics, 10, 197-214.

Ramos, M., Sedivi, B.M., \& Sweet, E.M. (1998). Computerized self-administered questionnaires. In: M.P. Couper, R.P. Baker, J. Bethlehem, C.Z.F. Clark, J. Martin, W.L. Nicholls II, \& J.M. O'Reilly (eds). Computer assisted survey information collection (pp. 389-408). New York: Wiley.

Riede, T. \& Dorn, V. (1991). Zur Einsetzbarkeit von Laptops in haushaltsbefragungen in der Bundesrepublik Deutschland [In German: Acceptance of laptops for household surveys in Germany]. Wiesbaden: Statistisches Bundesamt. Heft 20 der Schriftenreihe Ausgewählte Arbeitsunterlagen zur Bundesstatistik.

Samuels, J. (1994). From CAPI to HAPPI: A scenario for the future and its implications for research. Proceedings of the 1994 ESOMAR congress (Applications of new technologies).

Saltzman, A. (1992). Improving response rates in Disk-by-Mail Surveys, Sawtooth Software Conference Proceedings. Evanston: Sawtooth Software.

Saris, W.E. (1998). Ten years of interviewing without interviewers: The telepanel. In: M.P. Couper, R.P. Baker, J. Bethlehem, C.Z.F. Clark, J. Martin, W.L. Nicholls II, \& J.M. O'Reilly (eds). Computer assisted survey information collection (pp. 409-429). New York: Wiley.

Schaefer, D.R., \& Dillman, D.A. (1998). Development of a standard e-mail methodology; Results of an experiment. Public Opinion Quarterly, 62, 378-397.

Sebestik, J., Zelon, H., DeWitt, D., O'Reilly, J.M. \& McCowan, K. (1988). Initial experiences with CAPI. Paper presented at the U.S. Bureau of the Census Annual Research Conference, Washington, D.C.

Sikkel, D. (1998). The individual interview. In: M.P. Couper, R.P. Baker, J. Bethlehem, C.Z.F. Clark, J. Martin, W.L. Nicholls II, \& J.M. O'Reilly (eds). Computer assisted survey information collection (pp.147-165). New York: Wiley.

Sikkel, D., Hox, J., \& de Leeuw, E. (2008). Using auxiliary data for adjustment in longitudinal research. In: P. Lynn (Ed), Methodology of longitudinal surveys. New York: Wiley. An earlier version is available at

http://www.iser.essex.ac.uk/ulsc/mols2006/programme/data/papers/Sikkel.pdf

Sperry, S., Bittner, D. \& Branden, L. (1991). Computer assisted personal interviewing on the current beneficiary survey. Paper presented at the AAPOR 1991 conference, Phoenix, Arizona.

Statistics Sweden (1989). Computer assisted data collection in the labour force surveys: Report of technical tests. Stockholm: Statistics Sweden.

Schwarz, N., Strack, F., Hippler, H.J., and Bishop, G. (1991). The impact of administrative mode on response effects in survey measurement. Applied Cognitive Psychology, 5, 193-212. 
Thornberry, O., Rowe, B. \& Biggar, R. (1991). Use of CAPI with the U.S. National Health Interview Survey. Bulletin de Méthodologie Sociologique, 30, 27-43.

Tourangeau, R., \& Smith, T.W. (1998). Collecting sensitive information with different modes of data collection. In: M.P. Couper, R.P. Baker, J. Bethlehem, C.Z.F. Clark, J. Martin, W.L. Nicholls II, \& J.M. O'Reilly (eds). Computer assisted survey information collection (pp. 431-453). New York: Wiley.

Turner, C.F., Forsyth, B.H., O'Reilly, J.M., Cooley, P.C., Smith, T.K., Rogers, S.M., \& Miller, H.G. (1998). Automated self-interviewing and the survey measurement of sensitive behaviors. In: M.P. Couper, R.P. Baker, J. Bethlehem, C.Z.F. Clark, J. Martin, W.L. Nicholls II, \& J.M. O'Reilly (eds). Computer assisted survey information collection (pp.1-21). New York: Wiley.

Van Bastelaer, A.M.L., Kerssemakers, F.A.M. \& Sikkel, D. (1988). A test of the Netherlands continuous labour force survey with hand-held computers: Contributions to questionnaire design. Journal of Official Statistics, 4, 141-154.

Van Bastelaer, A.M.L., Kerssemakers, F.A.M. \& Sikkel, D. (1987). A test of the Netherlands continuous labour force survey with hand-held computers: Interviewer behaviour and data quality. In: CBS-Select 4; Automation in survey processing. Den Haag: Staatsuitgeverij.

Van Hattum, M., \& De Leeuw, E.D. (1999). A Disk-by-Mail survey of teachers and pupils in Dutch primary schools; Logistics and data quality. Journal of Official Statistics,.

Waterton, J.J. (1984). Reporting alcohol consumption: The problem of response validity. Proceedings of the section on survey research methods of the American Statistical Association (pp. 664-669). Washington D.C: ASA.

Waterton, J.J. \& Duffy, J.C. (1984). A comparison of computer interviewing techniques and traditional methods in the collection of self-report alcohol consumption data in a field survey. International Statistical Review, 2, 173-182.

Weeks, M.F. (1992). Computer-Assisted Survey Information Collection: A review of CASIC methods and their implication for survey operations. Journal of Official Statistics, 4, 445-466.

Weisband, S. \& Kiesler, S. (1996). Self-disclosure on computer forms: Meta-analysis and implications. Tucson: University of Arizona (Available on internet: http://www.al.arizona.edu/ weisband/chi/chi96.html).

Witt, K.J., \& Bernstein, S. (1992). Best practices in Disk-By-Mail Surveys, Sawtooth Software Conference Proceedings. Evanston: Sawtooth Software.

Witt, K.J. (1997). Best practices in interviewing via the internet. Sawtooth Software Conference Proceedings. Sequim, WA: Sawtooth software inc.

Woijcik,, M.S. \& Baker, R.P. (1992). Interviewer and respondent acceptance of CAPI. Proceedings of the Annual Research Conference, Washington DC: US. Bureau of the Census, 619-621.

Woijcik, M.S., \& Hunt, E. (1998). Training field interviewers to use computers: Past, present, and future trends. In: M.P. Couper, R.P. Baker, J. Bethlehem, C.Z.F. Clark, J. Martin, W.L. Nicholls II, \& J.M. O'Reilly (eds). Computer assisted survey information collection (pp. 331-349). New York: Wiley.

Yoshimura, O., \& Ohsumi, N. (2000). Some experimental surveys on the WWW Environments. Presented at the session Internet surveys and retrieval, International Meeting of the International Federation of Classification Societies (IFCS), Namur, Belgium, 2000 


\section{Appendix A}

\section{Taxonomy of Computer Assisted Data Collection Methods}

Presented is a systematic overview of survey methods and their computer assisted equivalents. General names: CADAC (Computer Assisted Data Collection), CASIC (Computer Assisted Survey Information Collection, CAI (Computer Assisted Interviewing).

\section{Data Collection Method Computer Assisted Form}

Interview

Face-to-face interview

Telephone interview

Self-administered form:

With interviewer present

Self-administered form:

Without interviewer

Mail survey equivalent

Telephone surveys equivalents

Panel research
CAPI (Computer Assisted Personal Interviewing)

CATI (Computer Assisted Telephone Interviewing)

CASI (computer assisted self interviewing).

V-CASI (question text on screen only: visual).

A-CASI (text on screen and also heard on audio)

CSAQ (computer assisted self administered questionnaire)

DBM (Disk by Mail) and EMS (Electronic Mail Survey), Websurvey, Internet survey

TDE (Touchtone Data Entry), IVR (Interactive Voice Response), ASR (Automatic Speech Recognition)

T-ACASI (Telephone -self-administered)

CAPAR (Computer Assisted Panel Research), Internet-panel, Web-panel, Access panel 